\title{
Contextualizing Transition: A Multiscale Approach to Making Resilience-Oriented and Place-Sensitive Strategies
}

\author{
Carmelina Bevilacqua ${ }^{(\mathbb{})}(\mathbb{D}$, Yapeng Ou $\mathbb{D}$, Pasquale Pizzimenti (D), \\ and Giada Anversa $\mathbb{D}$ \\ CLUDSLab, PAU Department, Mediterranea University of Reggio Calabria, \\ 89124 Reggio Calabria, Italy \\ cbevilac@unirc.it
}

\begin{abstract}
The widening of regional disparities remains a critical concern in the political and academic debate at global scale. Given the scope of the phenomenon, recent evidence indicates how growing regional divergences are increasingly jeopardizing social cohesion, fueling inequalities even within regions. The dichotomy between less developed and core regions seems to lose the centrality in the political agenda. An example is provided by the new geography of knowledge that is giving rise to a complex divergence that rests also on the different internal regional contexts' conditions. Regions are exposed to multidimensional shocks and stresses questioning territories' resilience and their ability to manage the transition process. The paper argues that regions need to enhance their resilience to transition-induced shock (dynamics) understanding this internal complex divergence. The paper introduces the multiscale approach as a dynamic factor in the policy-making process to capture the sensitiveness of places to adaptation, resilience-oriented performance, and the disruption of path dependency - which may be considered as the main obstacle for an equitable distribution of competitive advantage derived from innovation - and lead the post-carbon transition required by the European Green Deal. The analysis conducted rests on the conceptual framework of the Open Access Toolkit conceived for the TREnD Research Project funded by the Horizon 2020 Program. The conceptual framework adopted, underpinned by sets of indicators that couple context conditions with innovation performance, can be used to explore and identify in further studies EU settings that are more exposed to systemic risks associated with the transition process.
\end{abstract}

Keywords: Transition - Resilience $\cdot$ Peripheral areas $\cdot$ Context conditions · Multiscale approach

\section{Introduction}

The widening of territorial disparities remains a major concern in the political and academic debate in the European Union (EU). Recent evidence indicates how growing territorial divergences are increasingly jeopardizing social cohesion, fueling political instability and raising populist waves [1]. Technological progress and the associated 
new geography of knowledge reveal how disparities between and within (core vs periphery) regions are increasing. A growing literature advocates a reform of the current place-based approach to regional development, which is no longer effective especially for peripheral areas [2,3]. The widening of these disparities across EU is opening the discussion on how to couple distributive development policies with the benefits arising from agglomerations - to source new competitive advantages - for peripheral areas [1]. At the same time, the need to tackle the pressing climate change side-effects issue pushed the EU Institutions to frame and launch the European Green Deal. A new growth-strategy that "aims to transform the EU into a fair and prosperous society, with a modern, resource-efficient and competitive economy where there are no net emissions of greenhouse gases in 2050 and where economic growth is decoupled from resource use" [4] (p. 2). The Green Deal is part of the European Commission's Strategy to achieve the UN 2030 Agenda for Sustainable Development and target four major domains of transition: i) climate, ii) energy, iii) circular economy and iv) construction [4]. This requires a bold and comprehensive policy response to maximize benefits for health, quality of life, resilience and competitiveness [4]. The ability to respond to such pressing challenges is calling the attention of the EU policy debate on the concepts of "change" and the "transition" that it implies. EU has already recognized the need to ensure socially fair and just transitions of climate neutrality, digitalization and demographic change [5]. However, building a resilient society characterized by social fairness and prosperity through the post-2020 Cohesion Policy requires a conceptual and policy paradigmatic shift able to target effectively regions' disparities between core and peripheral areas. Despite territorial cohesion is one of the main objectives of the Cohesion Policy, it seems that investments (structural funds) in peripheral areas have not generated territorial convergences. Truly, peripheral areas showing demographic, labor market and economic disadvantages [6] - remain at the same development stage despite long-term structural funds in research and innovation. Such a paradox leads to find an answer to the following question: Why peripheral areas are not able to transform technological innovation into economic development opportunities as the core areas do?

Three factors appear accountable to answer this question. First, peripheral areas tend to be locked in an innovation paradox. Their need to increase R\&D intensity and innovation activities has long been recognized so as to catch up with their advanced counterparts [7]. Peripheral areas commonly underinvest in R\&D and innovation activities due to lower capacity to absorb public funds earmarked for the promotion of innovation and to invest in innovation related activities [7]. This apparent contradiction makes them unable to leverage their assets and potentials to boost R\&D and thereby build up competitive advantages. Second, peripheral areas show a mismatch between R\&D activity (knowledge creation) and economic development during the innovation process (knowledge transfer) in peripheral areas. This mismatch and the differences in regional capabilities to cope with technological resilience are widening the gap between core and peripheral areas [3]. The focus of EU Research and Innovation policies to drive structural change towards knowledge and innovation has worked well in filling the gap on the "R\&D" side but not on the "development" side - as R\&D developments are not transformed into productivity gains [8]. This effect raises policy questions regarding knowledge transfer processes [9]. Third, a new geography of development 
characterized by spatially concentrated technological innovation is ever growing. The economic integration process, both regionally and globally, has favored agglomeration economies, fueling the concentration of higher-level economic activities and services in major cities [10]. This effect is seemingly intensified with the rise of high tech-led innovation, leading to a new geography of knowledge more concentrated in metropolitan areas $[3,11,12]$. Whereas knowledge is an increasingly critical dimension of competitive advantage [11], its concentration in core areas - where productivity increases thanks to the concentration of skilled labor forces, companies and capitals hinders the innovation diffusion process. This results in a "new landscape" of regional disparities characterized by not only inter-regional but intra-regional divergences [13, 14]. Conversely, innovation diffusion can act as driver of industrial renewal and productivity growth, helping regions in industrial transition "catch up" with the more productive core/advanced areas [15].

This paper argues that on the one hand, during the transition to knowledge economy, regions' innovation and development performance and their resilience to transition-induced shocks are subject to their context conditions at different scales. On the other hand, addressing the more complicated issue of regional disparities requires a more nuanced recognition and understanding of places and relative context conditions at multiple territorial scales and typologies. Therefore, the multiscale approach to the analysis of territorial contexts allows sustaining regional economic agents to adapt and reconfigure their industrial, technological, network and institutional structures in an ever-changing economic system [16], thereby improving their resilience. In the light of the aforementioned factors, the multiscale approach is introduced as a dynamic factor in the policy-making process to capture the sensitiveness of place to adaptation, resilience-oriented performance, and the disruption of path dependency - which may be considered as the main obstacle for an equitable distribution of competitive advantage due to concentrated innovation. The paper is grounded on a complex European project, Transition with Resilience for Evolutionary Development (TREnD) - funded by the Horizon 2020 European Research Framework - aiming to: build an analytical framework of the context conditions of EU regions at different scales and the related trajectory of transition; and define how innovation can support transition-oriented regional/urban transformations and which factors can facilitate or hinder it. The multiscale approach proposed in this paper results from the logic behind the Open Access Toolkit (the analytical framework envisioned by the TREnD project) based on subregional units of data analysis likely to introduce sensitiveness measures of adaptation towards transition. In so doing, the paper first provides the research background and review of the literature on regional resilience, transition, territorial scales and territorial characteristics from the perspective of evolutionary economic geography. Then, it explains the multiscale approach by proposing an example consistent with the logic of the Open Access Toolkit in combining two indicators as explanatory variables respectively of context conditions and innovation performance. The results of the analysis of covariance on a metropolitan and urban-rural territorial basis are the starting point for a conceptual model to contextualize transition with resilience with a multiscale approach and characterize and an territorial contexts and related transition propensity of regions. 


\section{Literature Review}

\subsection{Resilience and Transition}

Resilience has become a very common and fashionable concept in the academic and political agenda. The responsiveness of economies in absorbing major global shocks (e.g. the economic crisis of 2008 , environmental risks due to climate change) has been the focus of several studies $[16,17]$. It is recognized that socio-economic systems need to be resilient to economic shocks to ensure both present and future economic stability, competitiveness, and high quality of life [18]. Resilience is a useful concept for analyzing how regions and localities respond to and recover from shocks, and how the spatial dynamics of economic growth and development are shaped over time under such shocks [19]. Increasingly, resilience is conceptualized not only as regions' ability to accommodate shocks but also for their long-term ability to develop new growth paths $[17,19]$. This means that resilience represents a trade-off between adaptation (changes within pre-existing paths) and adaptability (ability to develop new pathways) in a situation of structural change $[17,20]$. To operationalize the concept of resilience and thereby to better support policymaking and implementation, resilience needs to be properly measured. However, this is not a simple task. Currently, there is no mainstream approach to the measurement of resilience and, therefore, no uniform strategies for strengthening the resilience of economies [21]. One big challenge is the difficulty in adopting the conceptual framework of resilience for its application in the analysis of territories and their processes of change [22]. Indeed, developing indicator frameworks to measure resilience is a complex activity considering the diversity of context conditions at different territorial scales, the different geographical typologies and the continuous socio-economic changes due to rapid technological processes. Consequently, it is difficult to make a straightforward measurement of territorial resilience capacity [23]. Nevertheless, different groups of factors were proposed by scholars that may indicate and affect regional resilience (Table 1).

Table 1. Academic definitions of factors that may indicate and affect regional resilience [20].

\begin{tabular}{l|l}
\hline Author(s) & Resilience factors \\
\hline Martin (2012) & - regional dynamic growth \\
& - structure of the economy \\
& - regional export orientation \& specialization \\
& - human capital \\
& - innovation rate \\
& - business and corporate culture \\
& - localization of the region \\
& - institutional arrangement in the region \\
& - regional economic capacity \\
& - regional socio-demographic capacity \& community's \\
& capacity \\
\hline
\end{tabular}


Table 1. (continued)

\begin{tabular}{l|l}
\hline Author(s) & Resilience factors \\
\hline Briguglio et al. (2009) & - macroeconomic stability \\
& - micro-economic market efficiency \\
& - good governance \\
& - social development \\
\hline Koutský et al. (2012) & - main macroeconomic indicators \\
& - labor market indicators, etc. \\
\hline Stanickova and Melecký & - community links \\
$(2018)$ & - human capital and socio-demographic structure \\
& - labor market \\
& - economic performance \\
& - innovation, science and research \\
\hline
\end{tabular}

Also, international organizations developed and proposed different approaches and indicators frameworks with different metrics to measure resilience capacity (Table 2). It is worth noting that the factors and indicators listed in Table 2 generally show no territorial perspective with the exception of the development resilience analytical approach that considers different categories of indicators according to various spatial contexts.

Table 2. Resilience metrics [22]

\begin{tabular}{|c|c|c|c|c|}
\hline $\begin{array}{l}\text { Resilience } \\
\text { aspect }\end{array}$ & Definition & $\begin{array}{l}\text { Example } \\
\text { approach }\end{array}$ & $\begin{array}{l}\text { Organization } \\
\text { (year) }\end{array}$ & Metrics \\
\hline $\begin{array}{l}\text { Socio- } \\
\text { ecological }\end{array}$ & $\begin{array}{l}\text { The ability of a system } \\
\text { to absorb disturbance, } \\
\text { learn and adapt, and } \\
\text { self-organize }\end{array}$ & \begin{tabular}{|l|} 
Resilience \\
Assessment \\
Workbook for \\
Practitioners
\end{tabular} & $\begin{array}{l}\text { Resilience } \\
\text { Alliance } \\
(2010)\end{array}$ & $\begin{array}{l}\text { No use of specific } \\
\text { indicators, attributes } \\
\text { of factors that } \\
\text { enhance or erode } \\
\text { resilience }\end{array}$ \\
\hline Development & $\begin{array}{l}\text { The way households, } \\
\text { communities, nations } \\
\text { etc. can cope with } \\
\text { various stressors to } \\
\text { avoid poverty }\end{array}$ & $\begin{array}{l}\text { A Common } \\
\text { Analytical } \\
\text { Model for } \\
\text { Resilience } \\
\text { Measurement }\end{array}$ & FSIN (2014) & $\begin{array}{l}\text { Provides different } \\
\text { categories of } \\
\text { indicators that } \\
\text { depend on context }\end{array}$ \\
\hline $\begin{array}{l}\text { Socio- } \\
\text { economic }\end{array}$ & $\begin{array}{l}\text { Shock-absorption or } \\
\text { shock-counteraction } \\
\text { effects of policies on an } \\
\text { economy }\end{array}$ & $\begin{array}{l}\text { Economic } \\
\text { Resilience: } \\
\text { Definition and } \\
\text { Measurement }\end{array}$ & $\begin{array}{l}\text { World Bank } \\
\text { (2014) }\end{array}$ & $\begin{array}{l}\text { Provides a list of } \\
\text { indicators that can } \\
\text { be used to build a } \\
\text { resilience indicator }\end{array}$ \\
\hline Community & $\begin{array}{l}\text { The process of a } \\
\text { community to adapt to a } \\
\text { positive trajectory of } \\
\text { functioning after a } \\
\text { disturbance }\end{array}$ & $\begin{array}{l}\text { Community- } \\
\text { based } \\
\text { resilience } \\
\text { analysis (Co- } \\
\text { BRA) }\end{array}$ & UNDP (2013) & $\begin{array}{l}\text { Participatory } \\
\text { process, quantitative } \\
\text { indicators linked to } \\
\text { human, natural, } \\
\text { social, financial and } \\
\text { physical capital }\end{array}$ \\
\hline
\end{tabular}


Regional "resilience resonates with the growing importance of an evolutionary perspective within economic geography" [24] (p. 2). It helps conceptualize regions in a dynamic, holistic and systematic way [25] and understand the dynamics behind regional change [26]. It is recognized that the response to major shocks may exert a formative influence over how the economic landscape evolves, and - as an indicator of long-run regional growth patterns - regional resilience "can help understand the existence, persistence and evolution of long-run regional disparities" [24] (p. 4). This evolutionary perspective allows perceiving current regional disparities as the outcome of the long cycle of: 1) development in the economic structure, consisting of a major wave of technological innovation that began in the 1970s; and 2) regional evolutionary features, consisting of place-specific endowments of people and skills, firms and industries, formal and informal institutions, innovation capacities, and their reaction to change [1]. In this perspective, it is possible to formulate policies aimed at fostering a transition to a sustainable development, offering insights into the mechanisms that underlie innovations, structural change and transitions [27]. Sustainable transition calls for fundamental shifts in socio-technological systems that result from "system disrupting innovations" [28]. Tödtling and Trippl [28] propose systemic and multiscale policy concepts for new regional industrial path development, paying more attention to the direction of innovation and change. The EU has long pursued a structural change towards the knowledge-based society through the focus of public policies on Research and Innovation. However, such a policy approach is criticized for the lack of a systemic perspective and the disregard of untraded interdependencies and synergetic effects among firms, other organizations and policy makers [28]. Less developed territories have channeled fewer resources in this direction - as a proportion of GDP - despite their need to increase their R\&D intensity and innovation activities [7]. In addition, the limited interregional diffusion of technology and efficient production practices account for the large and persistent divergences in economic development across EU subnational regions [29].

\subsection{Territorial Scales and Territorial Characteristics}

As a response to the persistent socio-economic gaps among regions, the EU Cohesion Policy emphasizes the need to foster territorial development by capitalizing on territorial intrinsic attributes and strengths [30]. The different territorial scales (regional, sub-regional, metropolitan, city) reveal a stark difference between rural and urban regions and between rural regions close to cities and remote ones, which suggests a differentiated policy approach to address different challenges [31]. Moreover, economic systems are always prone to perturbations and shocks, such as recessions, major policy changes, currency crises and technological breakthroughs that can all disrupt and destabilize the path and pattern of economic growth [19]. It is within regional, urban and local economies and communities that such shocks and disturbances work out their effects and consequences [19]. Therefore, approaching territorial scales is relevant to regional development as it implies: 1) a shift from reaching convergence through redistributive regional policies towards endogenous approaches designed to foster territorial features in pursuing growth and competitiveness; 2) the deployment of interventions designed for different spatial scales, and an emphasis on the networking 
and connection of places; and 3) the strengthening of sub-national governments, through the devolution of political powers, or the adoption of multi-level governance [32]. During the 2014-2020 programming period, EU instruments introduced territorial and scalar varieties into the use of Structural Funds to address in an integrated way the territorial development needs of different regions and sub-regions, allowing interventions to be tailored to specificities of place and scale [30]. Many scholars argue that the need to territorialize policies and funds allows that innovation process is not blindly replicated across European regions, as replication without considering local conditions and broader regional network characteristics would produce a duplication of innovative efforts and fragmentation [33]. "With fragmentation, regional critical mass is barely attainable, the potential gains from scale and agglomeration vanishes, and the potential for complementarities within Europe diminishes" [33] (p. 6). Ultimately, this is likely to damage the sustainability of new regional pathways and reduce the effectiveness of the innovation policy deployed. It is no longer viable to assume that the same drivers of change are effective everywhere, and the appropriate drivers will respond and deliver required outcomes once the right levers are activated [26]. In this direction, an integrated multiscale approach is useful to provide meaningful information for policymaking, as it highlights local contexts features and potentials, integrates spatial scales, and addresses the local capacity of adaptation and transformation [34]. Together with territorial scales, regional characteristics have been increasingly considered as a factor pertinent to persisting regional disparities in the EU. First of all, the specific socioeconomic characteristics of each region affect the allocation of EU funds [35]. It is also recognized that local endowments and unique characteristics of regions are important territorial capital for regional development, and that the underdevelopment of lagging regions occurs due primarily to a failure to deliver effective investments and institutions [30]. Also, regional characteristics that affect resilience-related outcomes generally demonstrate an evolutionary feature, as it takes a long time to change them [21]. Regional characteristics, such as geographical, social, and institutional conditions, are considered closely related with the geographical heterogeneity of R\&D investments' productivity in the EU by an extensive literature [36]. These elements suggest how regional characteristics prove to be a relevant issue to be considered in designing more tailored strategies sensitive to local contexts. EU regional policies are generating disparate effects on different regions due to the joint force of multiple factors, such as the characteristics of the intervention, the structural characteristics and the specific nature of the territories involved, and finally the kind of context, meaning institutional skills, the social culture and policy-related objectives [37]. Indeed, countries showing an evident regional heterogeneity, including the ability to use structural funds and identify winning regional development strategies, are more likely to evidence the differentiation of the effects of the EU Cohesion Policy on different regions [37]. This is especially true at a time when the EU regional policies are centered on structural change. The changing structure of the economy interacts with the characteristics of regions to generate a pattern of development over time, which has increasingly resulted in divergence among regions especially since the new millennium [1]. Technological progress has increasingly stimulated output in advanced technologies, finance and advanced services sectors dependent on agglomeration economies concentrated in large metropolitan areas [1]. Consequently, regions vary not only in terms of technological 
and industrial competences, but also in terms of potential evolutionary trajectories [38]. This suggests that the potential evolutionary pathways of an innovation system depend on its inherited structures and existing dynamics including the adaptation or even radical transformation (ibid.) [37].

\section{Methodology}

To capture both the characteristics of different contexts from a multiscale perspective and their conditions for innovation, we use official statistics of different territorial typologies based on the Eurostat database. The multiscale approach proposed in this paper results from the logic behind the Open Access Toolkit (the analytical framework envisioned by the TREnD project) based on sub-regional units of data analysis likely to introduce sensitiveness measures of adaptation towards transition. It has been recognized that regional statistics alone cannot reveal the full and sometimes complex picture of what is happening at a finer level within the EU. Moreover, statistical information at a sub-regional level is an important tool for highlighting specific regional and territorial characteristics [39]. Therefore, a broad range of territorial typologies were integrated into the NUTS Regulation underlining the importance of subnational statistics as an instrument for targeted policymaking and a tool for understanding and quantifying the impact of policy decisions in specific territories [39]. The different typologies that constitute the building block for official statistics within the EU [39] follow a rigorous methodology in coupling the source of data from a plethora of administrative boundaries, according to each member State, and the need to ground the statistical observations beyond and inside the regional level, namely the NUTS 3 level. Three territorial typologies and their territorial characteristics are investigated: cluster types, local typology, and regional typology including other regional typologies (see Table 3).

Table 3. Definition of territorial typologies according to Eurostat [39]

\begin{tabular}{l|l|l}
\hline Classification & Territorial typology & Definition \\
\hline NUTS3 & Urban-Rural typology & $\begin{array}{l}\text { Urban-rural typology is applied to NUTS3 regions } \\
\text { by identifying three types of region based on the } \\
\text { share of the rural population: predominantly rural, } \\
\text { intermediate and predominantly urban regions }\end{array}$ \\
\cline { 2 - 3 } & Metropolitan regions & $\begin{array}{l}\text { These regions are defined as urban agglomerations } \\
\text { (NUTS3 regions or groups of NUTS3 regions) } \\
\text { where at least 50\% of the population lives inside a } \\
\text { functional urban area (FUA) composed of at least } \\
\text { 250,000 inhabitants }\end{array}$ \\
\hline $\begin{array}{l}\text { Local } \\
\text { Administrative } \\
\text { Units (LAU) }\end{array}$ & Degree of urbanization & $\begin{array}{l}\text { The local administrative units (LAUs) is codified as } \\
\text { cities, towns and suburbs or rural areas based on a } \\
\text { combination of geographical contiguity and } \\
\text { population density }\end{array}$ \\
\hline
\end{tabular}


Table 3. (continued)

\begin{tabular}{l|l|l}
\hline Classification & Territorial typology & Definition \\
\hline & $\begin{array}{l}\text { Cities, commuting zones and } \\
\text { Functional Urban Areas (FUA) }\end{array}$ & $\begin{array}{l}\text { A city is a LAU where a majority of the population } \\
\text { lives in an urban center of at least 50,000 inhabitants } \\
\text { A commuting zone contains the surrounding travel- } \\
\text { to-work areas of a city where at least } 15 \% \text { of } \\
\text { employed residents are working in the city } \\
\text { A FUA consists of a city and its commuting zone }\end{array}$ \\
\hline Cluster types & $\begin{array}{l}\text { Urban Cluster, urban centers, } \\
\text { rural grid }\end{array}$ & $\begin{array}{l}\text { Based on a grid of } 1 \mathrm{Km}^{2} \text { grid cells, the statistics are } \\
\text { collected based on urban cluster, urban centers and } \\
\text { rural grid defined according to the density of } \\
\text { population }\end{array}$ \\
\hline
\end{tabular}

From the literature review, we find how developing indicator frameworks to measure resilience is a complex task due to the complexity of each (territorial) system, making difficult a straightforward measurement of territories resilience capacity [23]. We argue that a multiscale approach is important to reveal the variance of the context conditions at different territorial scales. The set of indicators available from the Eurostat database are grouped into different categories, according to the territorial units' typology. The territorial units based on regional statistics, metropolitan regions and urban-rural typology are analyzed through six categories that include several indicators consistent with the main phenomenon explained by each category: 1) demography statistics; 2) economic account; 3) intellectual property; 4) business demography; 5) transport statistic; 6) labor market. The degree of urbanization based on Local Administrative Units (from cities to suburbs) provides information more oriented on explaining the local conditions: health, lifelong learning, education attainment, living condition, labor market, tourism, digital economy. The multiscale approach introduced in this paper plays a crucial role in building the conceptual framework of the TREnD project aiming to: i) understand how different context conditions at different territorial scales suggest different regional responses to innovation-induced shocks, ii) to achieve an effective innovation-oriented development through the transition management of shocks/stresses towards the post-carbon economy. This approach intends to gain a better understanding of regional contexts' diversity by indicating how territorial scales may respond to shocks stemming from socio-economic transitions. Besides, it is equally important to track the longitudinal behavior of territorial scales over time so as to help regions maintain long-term economic growth by facilitating the transition process [40]. Therefore, the multiscale approach is consistent with a fine database developed for the TREnD Project Open Access Toolkit - organized in such a way to apply data analytics methods and combine longitudinal and territorial trends of selected indicators. The aim of analysis conducted for this paper is twofold: 1) Providing evidence on the need to approach the issue of structural change, transition-oriented, of regions by highlighting the conditions and their potentials at different territorial units; 2) Coupling the multiscale approach with innovation policy in conceptualizing transition towards place-sensitive strategies. 


\subsection{Territorial Units and Multiscale Approach}

To provide evidence on the need to investigate regions' context conditions at different territorial scales concerning regional innovation performance we selected two indicators and two different territorial units, according to the NUTS Regulation [39]. The figures below show the consistency of metropolitan regions (see Fig. 1) and cities, towns and suburbs (see Fig. 2) by the degree of density. These units represent the geographical base maps to investigate the distribution of the two factors, selected from the TREnD project database for this paper. Figure 1 shows the distribution of metropolitan areas in EU Member States based on the degree of population density, and how they are mainly concentrated in the central-northern Europe.

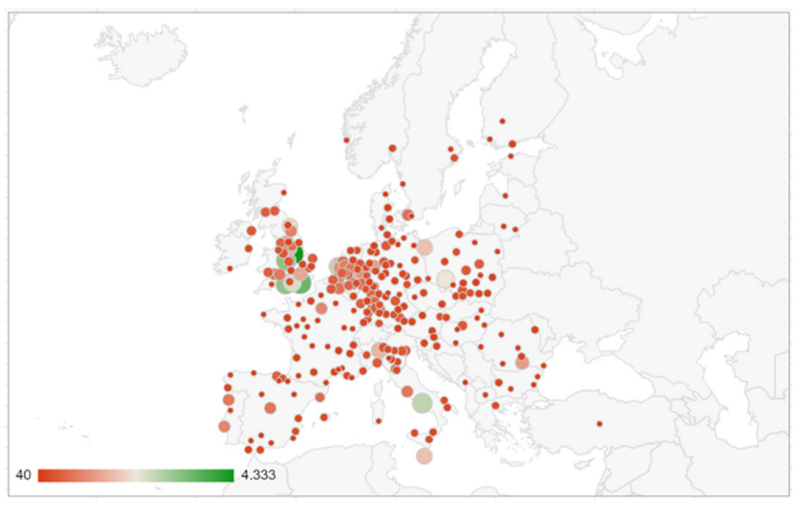

Fig. 1. Degree of population density per metropolitan areas 2016. Source: elaboration of the Authors from Eurostat [41]

Figure 2 shows the degree of population density according to the urban-rural typology. The value follows the territorial distinction in predominately urban areas, intermediate urban areas, predominately rural areas.

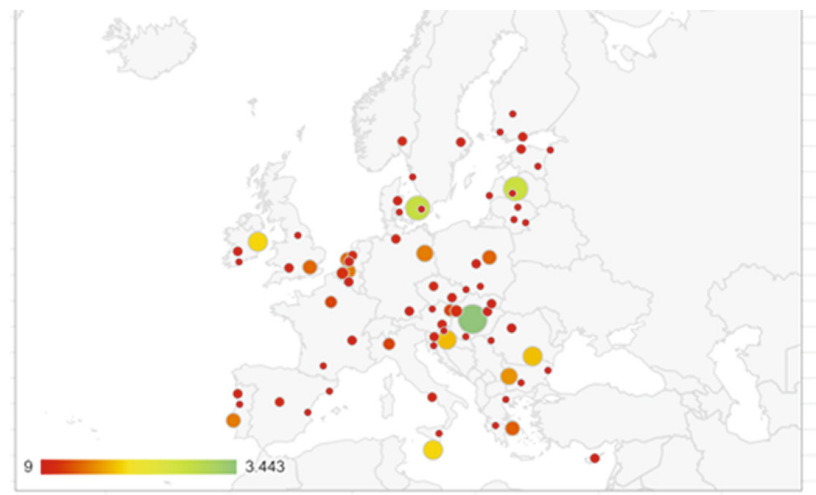

Fig. 2. EU Urban-rural areas: Degree of population density year 2016. Source: elaboration of the Authors from Eurostat [41] 
The two indicators selected are consistent with those factors that may indicate and affect regional resilience (Table 1) as explained in the literature review. We use the GDP per capita in 2017 and the European Union trade mark (EUTM) applications in 2017 at metropolitan and urban-rural levels to reveal the disparities in a multiscale perspective, investigating the macroeconomic conditions with innovation capacity. First, we organized the data in terms of frequency distribution with respect to the metropolitan areas and urban-rural areas (see Fig. 3).

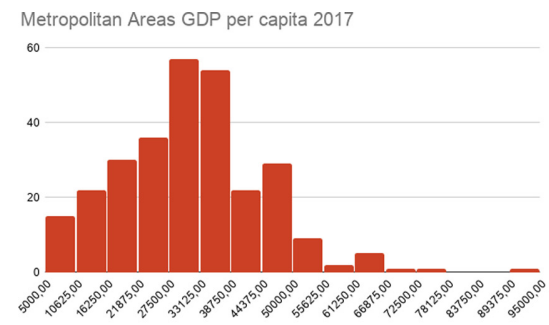

(a)

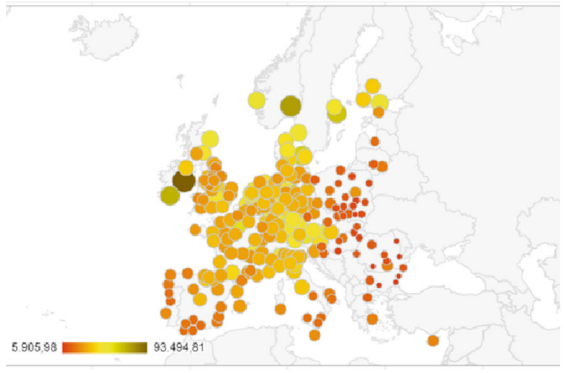

(c)

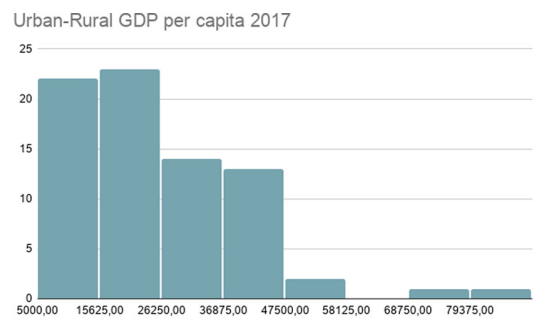

(b)

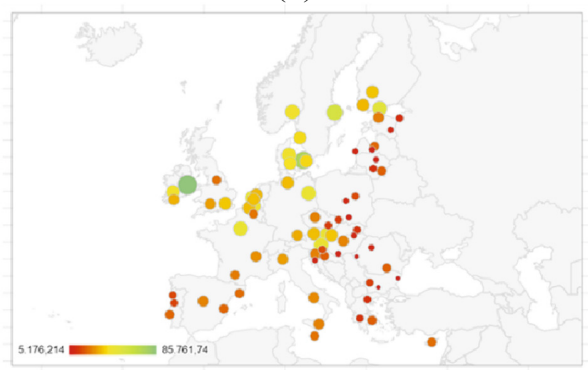

(d)

Fig. 3. GDP per capita distribution (2017) per metropolitan areas (a, c) and urban-rural typologies (b, d). Source: elaboration of Authors from Eurostat [41]

The frequency histograms for GDP per capita (see Fig. 3a, 3b) show how the distribution is different according to the territorial unit (see Fig. 3c, 3d), namely more concentrated in the medium range of values for metropolitan areas whereas more concentrated in the low range of values for urban-rural areas. With the aim to reveal a measurement of disparities, the distribution of GDP per capita is investigated through the GINI coefficient. The panel data is formed by metropolitan areas and urban-rural typology partitioned according to Member State. The GINI coefficient is a gauge of economic inequalities, based on population and income, and has several shortcomings in investigating the source of inequalities. To estimate the level of concentration, the GINI 
coefficient filters the two-dimensional area, the gap between the Lorenz curve and the equality line ranges between 0 in the case of perfect equality and 1 in the case of perfect inequality. Despite the limitations of the explanatory nature of the coefficient, we adopted it to provide a first, general overview of disparities beyond the traditional dichotomy of less developed and advanced regions. The panel data is compressively constituted by 344 observations. The investigation was first conducted to cover the overall European territory (344 observations) by considering the metropolitan areas and urban-rural areas independently from the Member States. The investigation was then directed to each Member State at metropolitan areas (268 observations) and urban-rural areas (76 observations) levels. The overall GINI coefficient calculated for GDP per capita and Population in 2017 among metropolitan and urban-rural areas in Europe is 0,64, whilst the values calculated for each Member State change in a range from a minimum of 0.06 to a maximum of 0,59 (see Table 4 ).

Table 4. GINI coefficient metropolitan and urban rural areas GDP per capita 2017. Source: Elaboration of the Authors from Eurostat [41] data and TREnD dataset.

\begin{tabular}{l|l|l|l|l}
\hline State & $\begin{array}{l}\text { GDP per capita } \\
(\text { EUR })\end{array}$ & $\begin{array}{l}\text { Highest metro region } \\
(\text { EUR })\end{array}$ & $\begin{array}{l}\text { Non-metro region } \\
\text { (EUR) }\end{array}$ & $\begin{array}{l}\text { GINI } \\
\text { coeff. }\end{array}$ \\
\hline Bulgaria & $7.274,57$ & $13.589,88$ & $4.851,30$ & 0,39 \\
\hline Romania & $9.545,78$ & $21.761,49$ & $5.905,98$ & 0,41 \\
\hline Latvia & $13.862,28$ & $17.796,99$ & $8.301,18$ & 0,17 \\
\hline Poland & $12.302,62$ & $26.663,96$ & $9.372,95$ & 0,39 \\
\hline Hungary & $12.661,35$ & $19.417,82$ & $9.638,77$ & 0,18 \\
\hline Croatia & $11.792,73$ & $16.315,20$ & $9.994,75$ & 0,12 \\
\hline Lithuania & $14.814,70$ & $20.567,84$ & $10.481,56$ & 0,20 \\
\hline Estonia & $17.949,59$ & $25.754,05$ & $11.725,19$ & 0,19 \\
\hline Slovakia & $15.610,95$ & $36.964,16$ & $12.705,78$ & 0,59 \\
\hline Greece & $16.319,02$ & $22.065,96$ & $13.296,87$ & 0,16 \\
\hline Czechia & $18.123,17$ & $27.277,47$ & $14.420,92$ & 0,27 \\
\hline Malta & $24.538,22$ & $25.238,12$ & $14.695,40$ & 0,20 \\
\hline Portugal & $18.876,97$ & $24.684,62$ & $16.257,66$ & 0,22 \\
\hline Slovenia & $20.814,06$ & $29.404,51$ & $18.036,41$ & 0,09 \\
\hline United & $35.651,07$ & $54.791,24$ & $22.304,55$ & 0,51 \\
\hline Kingdom & & & & 0,12 \\
\hline Spain & $25.067,02$ & $37.261,51$ & $24.817,64$ & 0,18 \\
\hline France & $34.301,92$ & $58.104,84$ & $24.817,64$ & 0,27 \\
\hline Italy & $28.469,55$ & $47.935,34$ & $24.906,11$ & 0,27 \\
\hline Ireland & $61.472,95$ & $93.494,81$ & $26.060,10$ & 0,12 \\
\hline Belgium & $38.686,05$ & $52.576,15$ & $32.534,43$ & $($ continued $)$ \\
\hline Germany & $39.623,51$ & $64.482,23$ & &
\end{tabular}


Table 4. (continued)

\begin{tabular}{l|l|l|l|l}
\hline State & $\begin{array}{l}\text { GDP per capita } \\
(\text { EUR })\end{array}$ & $\begin{array}{l}\text { Highest metro region } \\
\text { (EUR) }\end{array}$ & $\begin{array}{l}\text { Non-metro region } \\
\text { (EUR) }\end{array}$ & $\begin{array}{l}\text { GINI } \\
\text { coeff. }\end{array}$ \\
\hline Netherlands & $43.148,89$ & $54.413,93$ & $35.795,03$ & 0,14 \\
\hline Austria & $42.164,01$ & $54.949,19$ & $37.271,75$ & 0,33 \\
\hline Finland & $40.674,34$ & $66.166,69$ & $39.837,66$ & 0,23 \\
\hline Denmark & $50.933,69$ & $62.971,07$ & $44.265,03$ & 0,11 \\
\hline Norway & $61.530,46$ & $76.323,25$ & $57.214,29$ & 0,06 \\
\hline Sweden & $47.545,47$ & $66.166,69$ & $39.837,66$ & 0,23 \\
\hline
\end{tabular}

The GINI coefficient as measure of disparities offers interesting insights under the lens of the multiscale approach. Table 4 aggregates the results by member states, whilst the figure below (Fig. 4) shows how the value of the GINI coefficient increases according to the disparities between metropolitan and urban-rural areas within each state.

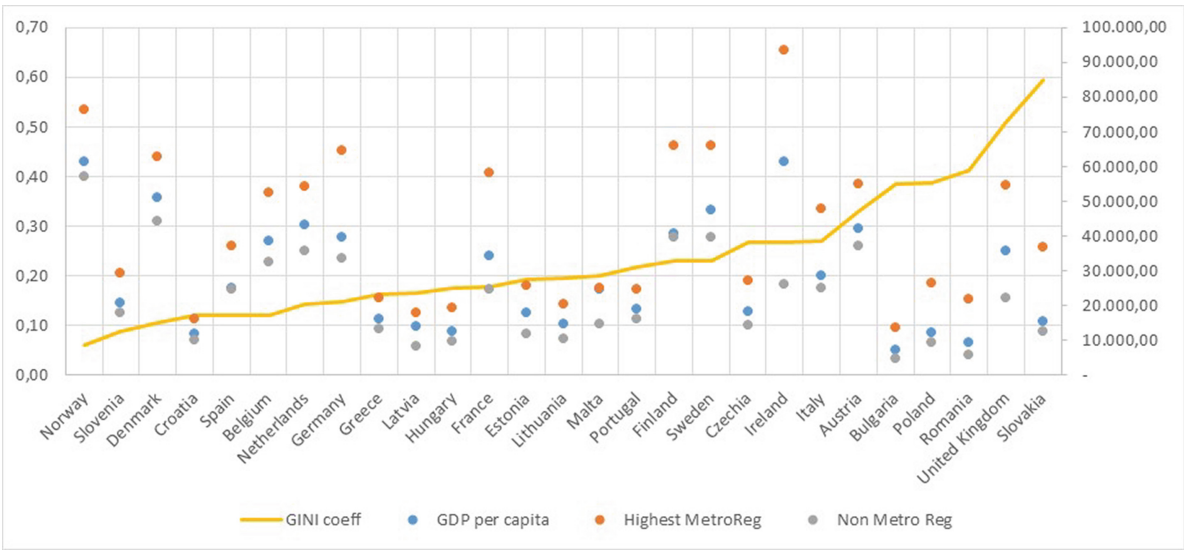

Fig. 4. GINI coefficient for territorial typologies. Source: elaboration of the Authors from Eurostat [41]

The second indicator selected for the investigation rests on the European Union Trade Mark (EUTM) applications in 2017. Eurostat provides a set of indicators based on trade marks - a process that allows creators to establish protection for their industrial property - reflecting also the non-technological innovation in every sector of economic life, including services. In this context, indicators based on trade mark data can provide a link between innovation and the market [42]. For the purpose of this paper it was selected the number of EUTM per millions of inhabitant's indicator. 
Metropolitan areas - European Trade Marks 2017

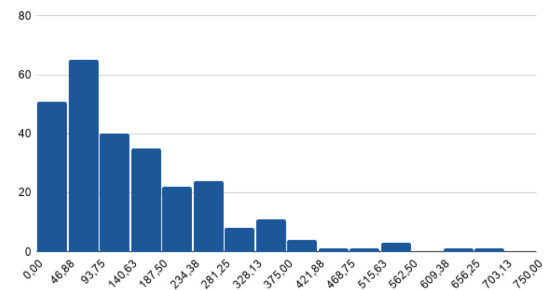

(a)

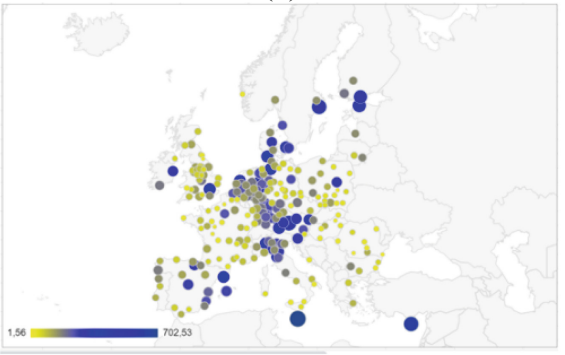

(c)
Urban-rural areas - European Trade Marks 2017

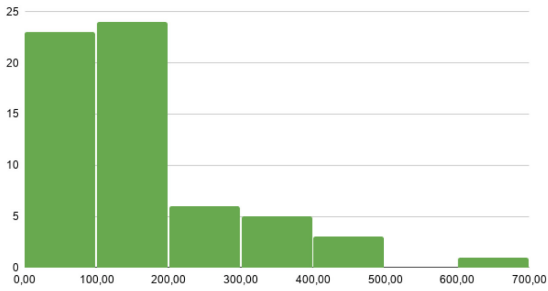

(b)

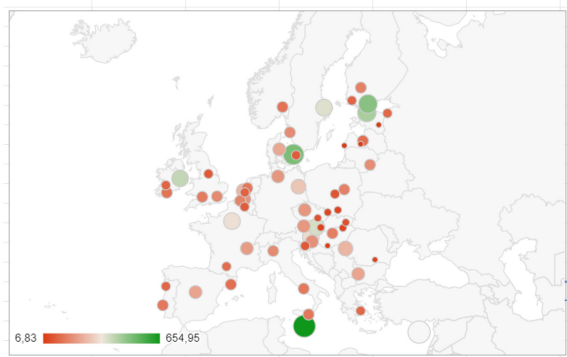

(d)

Fig. 5. European Trade Marks (2016) at metropolitan (a, c) and urban-rural scales (b, d) (number per millions of inhabitants). Source: elaboration of the Authors from Eurostat [41]

Figure 5 shows the distribution of the EUTM indicators by metropolitan areas and urban-rural areas. Based on the frequency distribution of the indicator across the two territorial scales, we applied a cluster analysis to classify the values according to: i) low, ii) medium, iii) medium-high, and iv) high performances in terms of number of EUTM per million of inhabitants with respect to the territorial units, in a range of values between 0 and 1 . The two figures below (see Fig. 6,7) display the results of cluster analysis aggregated by Members States against the EUTM indicators analyzed by Metropolitan areas (268 observations) and urban-rural areas (76 observations).

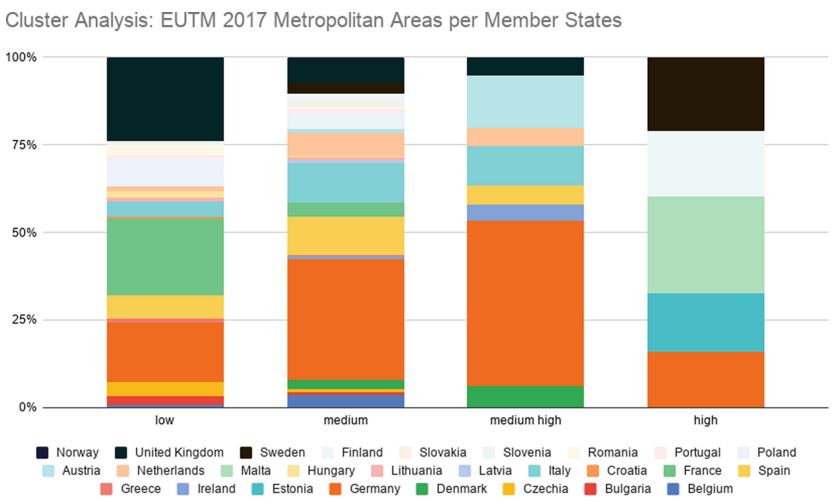

Fig. 6. Cluster analysis aggregated by Member State against the EUTM indicators analyzed by Metropolitan areas (268 observations). Source: elaboration of the Authors from Eurostat [41] 


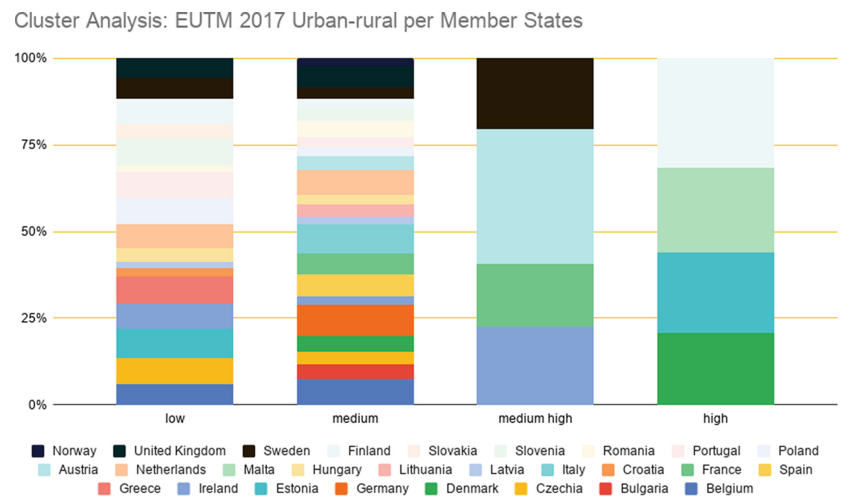

Fig. 7. Cluster analysis aggregated by Member State against the EUTM indicators analyzed by urban-rural areas (76 observations). Source: elaboration of the Authors from Eurostat [41]

To reveal how the proposed multiscale approach explains the relation between conditions and innovation performance, we applied the covariance analysis to express the degree of correlation between the conditions, described by the territorial disparities against the GDP per capita at metropolitan and urban-rural areas, and the innovation performance values from the cluster analysis. Each level of performance was correlated with the level of internal regional disparity according to the metropolitan and urbanrural areas to identify the position of each Member State with respect to the level of inequality and the corresponding level of performance. The figure below (Fig. 8) displays the results concerning the urban-rural areas. Each quadrant identifies the location of States based on the correlation between the level of performance and the level of disparities in terms of urban-rural areas.

The first bottom left quadrant (Fig. 8a) shows the correlation of low level of performance with the disparities inside the urban-rural areas of each state. Next, the second bottom right quadrant (Fig. 8b) shows the correlation of medium level of performance with the disparities inside the urban-rural areas of each state, the third top left (Fig. 8c) quadrant concerning the medium-high level and the fourth quadrant (Fig. 8d) the high level.

\subsection{Results and Discussions}

The objective of the analysis conducted was to introduce a multiscale approach to target policy actions based on contexts' characteristics and needs unleashing their potentials according to the TREnD Project Open Access Toolkit. The analysis takes into account two indicators as explanatory of context conditions and innovation performance to frame the multiscale approach. Context indicators provide simple and reliable information on context's variables [43]. Moreover, as an instrument of monitoring and assessment for measuring the achievement of a specific objectives' set and aggregated by sector or macro-area of intervention (demographic, social, environmental and economic), context indicators are important to enable an integrated reading of territorial dynamics [44]. The European Commission adopts context indicators to 


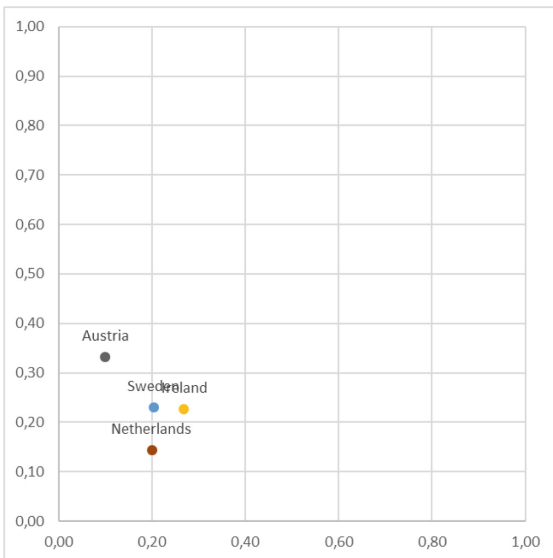

(c)

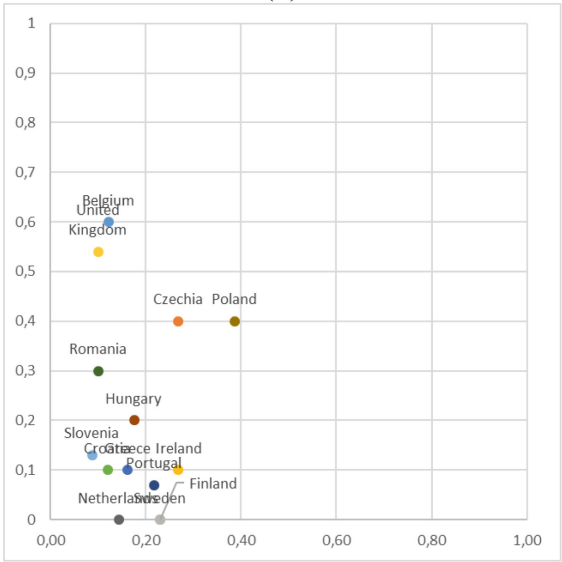

(a)

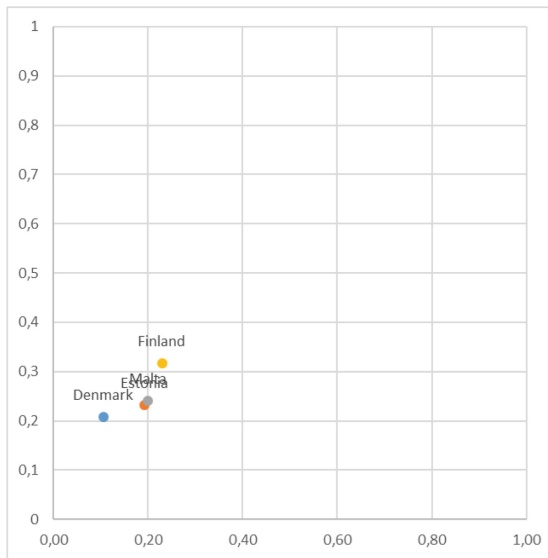

(d)

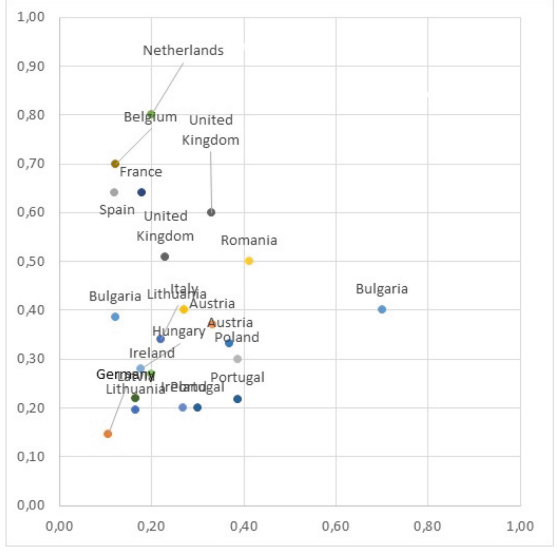

(b)

Fig. 8. Relationship between conditions and innovation performance in Urban-Rural areas by member states. Source: elaboration of the Authors from Eurostat [41]

monitor changes of countries' specific variables focusing on the basis of macrocategories of indicators [43]. Innovation performance indicators concern both $R \& D$ indicators and technological transfer related to business and entrepreneurial capacity. The methodology used to explain the multiscale approach is articulated in different steps consistent with the logic underlying the construction of the Open Access Toolkit within the TREnD project rationale. Results suggest how the interregional disparities, analyzed against metropolitan and urban-rural areas, coupled with the clustered level of innovation performance, depict different geographical patterns, which move forward the traditional dichotomy between lagging regions and core regions. Based on the level of performance (innovation) at urban-rural level, the results in the Fig. 8 display how the position of Member States varies across the different quadrants by taking into account the internal disparities. Although the paper proposes the multiscale approach 
by analyzing only two indicators, the results may converge on revealing the phenomenon of how the new geography of knowledge concentration is giving rise to a complex divergence that rests on different conditions within regional contexts. It could be argued that the multiscale approach can help make effective place-sensitive strategies for the transition towards the achievement of the Green New Deal objectives. It can capture the divergence of capabilities to cope with shocks stemming from technological progress both among and within regions.

\subsection{Conclusions}

The paper is aimed to introduce a multiscale approach - grounded on the TREnD Research Project Open Access Toolkit - to address the issue of transition-oriented structural change of regions by highlighting the context conditions and their potentials at different territorial scales. The European Green Deal has introduced a new "growth" strategy for the European Union [5]. It is a comprehensive, ambitious and bold plan whereby climate, environmental and social protection goals permeate its five "building blocks": global competitiveness, sustainable growth and digital growth agenda, socially just, empowering and inclusive growth strategies. Such transformative pathways help set the stage for policy actions in the upcoming post-2020 programming period [5], making a sharp - and yet much needed - shift in the EU policy-making approach. A paradigmatic shift from a primary push towards productivity and competitiveness goals to the pursuit of a "renewed" concept of competitiveness - socially just and environmentally responsible - by means of a reformed pan-European economic model. The adoption of a new growth and development strategy underpins a strong Transition, which can and will eventually pose additional challenges. Despite addressing climate change issues, environmental risk and other pressures is a common endeavor across Member States, not all regions - and sub-regions - will be equally impacted by and able to react to the multi-faceted Transition-induced shocks ahead. To this end, the "Just Transition Mechanism" [4] comes to the fore to sustain European regions displaying high degrees of dependence on traditional modes of productions and consumptions schemes (e.g. carbon-intensive activities, consumer choice and routines) in several domains, hence scarcely resilient. From a spatial and temporal standpoint, both inter- and intra-regional resilience is intra - is highly fragmented and sharply influenced by the complexity of contexts' characteristics that vary over time and across spatial scales. Therefore, we argue that the proposed multiscale may guide the identification of the specific context conditions that can be embodied within the Just Transition Mechanism, allowing peripheral regions to be more resilient to transition-induced shocks [1]. The multiscale approach, indeed, embraces the concept of regional resilience as the long-term aggregated ability of socio-economic systems to withstand transition-induced shocks by rapidly re-organizing their socio-political, institutional, economic, knowledge structures and networks, whereby developing new growth paths $[17,19,20]$. To this end, the multiscale approach intends to integrate and bridge two concepts/approaches which we posit as being inter-dependent: i) scale-sensitive recognition of territorial features and conditions [1, 3, 45] and ii) resilience to Transition-induced shocks [5]. Our framework, enriched by sets of indicators that couple conditions with performance, can be used to explore and identify in further 
studies EU settings - profiled and classified using a place and scale-sensitive and evolutionary approach (longitudinal) - that are more exposed to systemic risks associated with the transition process.

Acknowledgements. This research is part of the TREnD project (Transition with Resilience for Evolutionary Development) which has received funding from the European Union's Horizon 2020 research and innovation program under the Marie Skłodowska-Curie grant agreement No. 823952.

\section{References}

1. Iammarino, S., Rodríguez-Pose, A., Storper, M.: Why Regional Development matters for Europe's Economic Future (2017). https://ec.europa.eu/regional_policy/sources/docgener/ work/201707_regional_development_matters.pdf. Accessed 21 Jan 2020

2. Hassink, R.: Advancing place-based regional innovation policies. In: González-López, M., Asheim, B.T. (eds.) Regions and Innovation Policies in Europe: Learning from the Margins (2020). Edward Elgar, Cheltenham (2020)

3. Hassink, R., Gong, H.: Six critical questions about smart specialization. Eur. Plan. Stud. 27 (10), 2049-2065 (2019)

4. European Commission: The European Green Deal. Communication from The Commission To The European Parliament, The European Council, The Council, The European Economic And Social Committee And The Committee Of The Regions. Brussels, 11.12.2019. COM(2019) 640 final. https://ec.europa.eu/info/sites/info/files/european-green-deal-communication_en. pdf. Accessed 19 Jan 2020

5. European Commission: A Strong Social Europe for Just Transitions. Communication from the Commission to the European Parliament, the Council, the European Economic and Social Committee and the Committee of the Regions (2020). https://eur-lex.europa.eu/legalcontent/EN/TXT/?uri=COM:2020:14:FIN. Accessed 31 Jan 2020

6. ESPON: Inner Peripheries in Europe: Possible Development Strategies to Overcome Their Marginalising Effects (2018). https://www.espon.eu/inner-peripheries-brief. Accessed 19 Jan 2020

7. Oughton, C., Landabaso, M., Morgan, K.: The regional innovation paradox: innovation policy and industrial policy. J. Technol. Transfer 27(1), 97-110 (2002)

8. Lopes, J., Ferreira, J.J., Farinha, L.: Innovation strategies for smart specialisation (RIS3): Past, present and future research. Growth Change 50(1), 38-68 (2019)

9. Andries, P., Callaert, J., Debackere, K., Du Plessis, M., Glänzel, W., Thijs, B.: Specialisation profiles and diagnostic tools, pp. 150-168 (2013). In: OECD Innovation-driven Growth in Regions: The Role of Smart Specialisation. https://www.oecd.org/sti/inno/smartspecialisation.pdf. Accessed 19 Jan 2020

10. Lagendijk, A., Lorentzen, A.: Proximity, knowledge and innovation in peripheral regions. On the intersection between geographical and organizational proximity. Eur. Plann. Stud. 15 (4), 457-466 (2007)

11. Balland, P.A., Rigby, D.: The geography of complex knowledge. Econ. Geogr. 93(1), 1-23 (2017)

12. Compagnucci, F., Cusinato, A.: The knowledge economy: a new source of regional divergence? Revue d'Économie Régionale \& Urbaine 2, 365-393 (2014) 
13. Butkus, M., Cibulskiene, D., Maciulyte-Sniukiene, A., Matuzeviciute, K.: What is the evolution of convergence in the EU? decomposing EU disparities up to NUTS 3 level. Sustainability 10, 1-37 (2018). https://doi.org/10.3390/su10051552

14. Iammarino, S., Rodríguez-Pose, A., Storper, M.: Regional inequality in Europe: evidence, theory and policy implications. J. Econ. Geogr. 19(2), 273-298 (2019)

15. OECD: Regions in Industrial Transition: Policies for People and Places. Paris: OECD Publishing (2019). https://doi.org/10.1787/c76ec2a1-en. Accessed 19 Jan 2020

16. Balland, P.A., Rigby, D., Boschma, R.: The technological resilience of US cities. Cambridge J. Reg. Econ. Soc. 8(2), 167-184 (2015)

17. Boschma, R.: Towards an evolutionary perspective on regional resilience. Reg. Stud. 49(5), 733-751 (2015). https://doi.org/10.1080/00343404.2014.959481

18. Bruneckiene, J., Pekarskiene, I., Palekiene, O., Simanaviciene, Z.: An assessment of socioeconomic systems' resilience to economic shocks: the case of lithuanian regions. Sustainability 11(566), 1-24 (2019). https://doi.org/10.3390/su11030566

19. Martin, R., Sunley, P.: On the notion of regional economic resilience: conceptualization and explanation. J. Econ. Geogr. 15, 1-42 (2015). https://doi.org/10.1093/jeg/lbu015

20. Stognief, N., Walk, P., Schöttker, O., Oei, P.-Y.: Economic resilience of German lignite regions in transition. Sustainability 11(21), 1-17 (2019)

21. Stanickova, M., Melecký, L.: Understanding of resilience in the context of regional development using composite index approach: the case of European Union NUTS-2 regions. Reg. Stud. 5(1), 231-254 (2018). https://doi.org/10.1080/21681376.2018.1470939

22. Sánchez-Zamora, P., Gallardo-Cobos, R.: Diversity, disparity and territorial resilience in the context of the economic crisis: an analysis of rural areas in Southern Spain. Sustainability 11, 1-21 (2019). https://doi.org/10.3390/su11061743

23. European Commission: Building and measuring Europe's resilience (2017). https://ec. europa.eu/newsroom/ENV/item-detail.cfm?item_id=604587\&newsletter_id=300\&utm_ source=env_newsletter\&utm_medium $=$ email\&utm_campaign=Beyond $\% 20$ GDP\&utm_ content=Building\%20and $\% 20$ measuring\%20Europes\%20resilience\&lang=en. Accessed 29 Jan 2020

24. Martin, R.: Regional economic resilience, hysteresis and recessionary shocks. J. Econ. Geogr. 12(1), 1-32 (2012)

25. Hassink, R.: Regional resilience: a promising concept to explain differences in regional economic adaptability? Cambridge J. Reg. Econ. Soc. 3, 45-58 (2010). https://doi.org/10. 1093/cjres/rsp033

26. Christopherson, S., Michie, J., Tyler, P.: Regional resilience: theoretical and empirical perspectives. Cambridge J. Reg. Econ. Soc. 3, 3-10 (2010). https://doi.org/10.1093/cjres/ rsq004

27. Van den Bergh, J.C.J.M., Oosterhuis, F.: An evolutionary-economic analysis of energy transitions. In: Van den Bergh, J.C.J.M., Bruinsma, F.R. (eds.) Managing the Transition to Renewable Energy: Theory and Practice from Local. Regional and Macro Perspectives. Edward Elgar, Cheltenham, UK (2008)

28. Tödtling, F., Trippl, M.: Regional innovation policies for new path development - beyond neo-liberal and traditional systemic views. Eur. Plan. Stud. 26(9), 1779-1795 (2018). https:// doi.org/10.1080/09654313.2018.1457140

29. Beugelsdijk, S., Klasing, M.J., Milionis, P.: Regional economic development in Europe: the role of total factor productivity. Reg. Stud. 52(4), 461-476 (2018). https://doi.org/10.1080/ 00343404.2017.133411

30. O’Brien, P., Sykes, O., Shaw, D.: The evolving context for territorial development policy and governance in Europe-From shifting paradigms to new policy approaches. L'Information géographique 79(1), 72-97 (2015) 
31. Garcilazo, E.: Growth Trends and Characteristics of OECD Rural Regions. Garcilazo, Enrique. OECD Regional Development Working Papers, No. 2013/10 (2013). OECD Publishing, Paris. https://doi.org/10.1787/5k4522x3qk9q-en

32. Bachtler, J.: Place-based policy and regional development in Europe. Horizons 10(44), 5458 (2010)

33. Crespo, J., Balland, P.A., Boschma, R., Rigby, D.: Regional Diversification Opportunities and Smart Specialization Strategies. European Commission, Directorate-General for Research and Innovation (2017). https://ec.europa.eu/research/openvision/pdf/rise/crespoballand-boschma-rigby_regional_diversification.pdf. Accessed 13 Jan 2020

34. Singh-Peterson, L., Underhill, S.J.R.: A multi-scalar, mixed methods framework for assessing rural communities' capacity for resilience, adaptation, and transformation. Commun. Dev. 48(1), 124-140 (2017). https://doi.org/10.1080/15575330.2016.1250103

35. Coppola, G., Destefanis, S., Marinuzzi, G., Tortorella, W.: The impact of EU funds and national policies on regional growth, 65-79 (2018). The Impact of Cohesion Policies in Europe and Italy. Senato della Repubblica. http://www.senato.it/service/PDF/PDFServer/ BGT/01083823.pdf. Accessed 28 Jan 2020

36. Crescenzi, R., Rodríguez-Pose, A.: R\&D, Socio-Economic Conditions, and Regional Innovation in the U.S. Growth Change 44(2), 287-320 (2018)

37. Pellegrini, G., Tortorella, W. The Main Evidence, 7-11(2018). The Impact of Cohesion Policies in Europe and Italy. Senato della Repubblica. http://www.senato.it/service/PDF/ PDFServer/BGT/01083823.pdf. Accessed 28 Jan 2020

38. McCann, P., Ortega-Argilés, R.: Smart specialisation, regional growth and applications to EU cohesion policy. Economic Geography Working Paper 2011: Faculty of Spatial Sciences, University of Groningen (2011)

39. European Union: Eurostat Methodological manual on territorial typologies (2018 Edition). Luxembourg: Publications Office of the European Union EU (2019)

40. Eurostat website: Eurostat Database (2020). available at https://ec.europa.eu/eurostat/data/ database. Accessed 21 Jan 2020

41. Hallegatte, S.: Economic Resilience Definition and Measurement. Policy Research Working Paper 6852, The World Bank Climate Change Group Office of the Chief Economist (2014). http://documents.worldbank.org/curated/en/350411468149663792/pdf/WPS6852.pdf. Accessed 21 Jan 2020

42. Eurostat website: European Union trade mark (EUTM), Reference Metadata in Euro SDMX Metadata Structure (ESMS). Compiling agency: Eurostat, the statistical office of the European Union (Eurostat Metadata - EUTM. https://ec.europa.eu/eurostat/cache/metadata/ en/ipr_t_esms.htm. Accessed 20 Mar 2020

43. European Union: Connecting the Development Community. CAPACITY4DEV. https://europa. eu/capacity4dev/evaluation_guidelines/minisite/en-methodological-bases-and-approach/ evaluation-tools/context-indicators/detailed-presentat\#anchor1. Accessed 18 Jan 2020

44. Prezioso, M.: Cohesion policy: methodology and indicators towards common approach. Romanian J. Reg. Sci. 2(2) 1-32 (2008). https://art.torvergata.it/retrieve/handle/2108/20466/ 27812/P1-PREZIOSO.pdf. Accessed 21 Jan 2020

45. Rodríguez-Pose, A.: The revenge of the places that don't matter (and what to do about it). Cambridge J. Reg. Econ. Soc. 11(1), 189-209 (2018) 
Open Access This chapter is licensed under the terms of the Creative Commons Attribution 4.0 International License (http://creativecommons.org/licenses/by/4.0/), which permits use, sharing, adaptation, distribution and reproduction in any medium or format, as long as you give appropriate credit to the original author(s) and the source, provide a link to the Creative Commons license and indicate if changes were made.

The images or other third party material in this chapter are included in the chapter's Creative Commons license, unless indicated otherwise in a credit line to the material. If material is not included in the chapter's Creative Commons license and your intended use is not permitted by statutory regulation or exceeds the permitted use, you will need to obtain permission directly from the copyright holder.

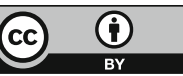

